\title{
Effect of pulsed electromagnetic field on inflammatory pathway markers in RAW 264.7 murine macrophages
}

This article was published in the following Dove Press journal:

Journal of Inflammation Research

II March 2013

Number of times this article has been viewed

\author{
Christina L Ross ${ }^{1,2}$ \\ Benjamin S Harrison ${ }^{2}$ \\ 'Akamai University, Department \\ of Energy Medicine, Hilo, HI, \\ USA; ${ }^{2}$ Wake Forest Institute for \\ Regenerative Medicine, Wake Forest \\ Baptist Health, Winston-Salem, \\ NC, USA
}

\begin{abstract}
In the treatment of bacterial infections, antibiotics have proven to be very effective, but the way in which antibiotics are dosed can create a lag time between the administration of the drug and its absorption at the site of insult. The time it takes an antibiotic to reach therapeutic levels can often be significantly increased if the vascular system is compromized. Bacteria can multiply pending the delivery of the drug, therefore, developing treatments that can inhibit the inflammatory response while waiting for antibiotics to take effect could help prevent medical conditions such as septic shock. The aim of this study was to examine the effect of a pulsed electromagnetic field on the production of inflammatory markers tumor necrosis factor (TNF), transcription factor nuclear factor kappa B (NFkB), and the expression of the $A 20$ (tumor necrosis factor-alpha-induced protein 3 ), in an inflamed-cell model. Lipopolysaccharidechallenged cells were exposed to a pulsed electromagnetic field at various frequencies in order to determine which, if any, frequency would affect the TNF-NFkB- $A 20$ inflammatory response pathway. Our study revealed that cells continuously exposed to a pulsed electromagnetic field at $5 \mathrm{~Hz}$ demonstrated significant changes in the downregulation of TNF- $\alpha$ and NFkB and also showed a trend in the down regulation of $A 20$, as compared with controls. This treatment could be beneficial in modulating the immune response, in the presence of infection.
\end{abstract}

Keyword: TNFAIP3, pulsed electromagnetic field, macrophages, TNF, NFkB

\section{Introduction}

The anti-inflammatory applications of pulsed electromagnetic field (PEMF) are well known. ${ }^{1-3}$ Immunological studies show that PEMF, even low-intensity PEMF, can interact with cells and tissues. ${ }^{2,4}$ For example, the effect of PEMF on the immune system in phagocytic cells alone has attracted attention because of the role that extremelylow frequency electromagnetic field (ELF-EMF) plays in decreasing the growth rate of bacteria. ${ }^{3}$ Interest in PEMF therapy has increased rapidly in recent years due to its advantages over other treatments. ${ }^{5}$ Benefits include low cost, ready availability, ease of localized application, few if any side effects, and indefinite shelf life. ${ }^{6}$ Because PEMF can be applied almost immediately after insult and can penetrate even poorly vascularized tissue, it would be beneficial to explore the effect of PEMF on immune response as a potential adjunct to pharmaceuticals, such as intravenous antibiotics $\beta$-lactams, aminoglycosides, macrolides, and corticosteroids.

Inflammatory cell signaling is part of a complex system of communication that governs basic cellular activities and coordinates cell behavior. During inflammatory responses, tumor necrosis factor (TNF) and interleukin-1 (IL-1) signals activate transcription factor nuclear factor kappa $\mathrm{B}(\mathrm{NFkB})$, which regulates the transcription of
Correspondence: Benjamin S Harris

$\mathrm{Tel}+\mathrm{I} 3367137292$

Fax +13367137290

Email bharriso@wakehealth.edu 
proinflammatory genes. TNF is a potent cytokine and a critical regulator of apoptosis, inflammation, and immunity. ${ }^{7} \mathrm{TNF}-\alpha$ is important for both local and systemic inflammation and is a powerful inducer of $\mathrm{NFkB}$, which is crucial to the propagation of cytokine responses. NFkB is highly involved in the pathway leading from pathogen recognition to proinflammatory cytokine production. ${ }^{8}$ It controls the transcription of cytokines and antimicrobial effectors as well as genes that regulate cellular differentiation, proliferation, and survival. Based on their ability to inhibit NFkB-dependent expression, inhibitor kappa B alpha (IkB- $\alpha$ ) and $A 20$ (tumor necrosis factor-alphainduced protein 3) are commonly thought of as negative feedback regulators in the TNF-NFkB signaling pathway. ${ }^{9}$ A20 (also known as TNFAIP3) is a genetic protein that plays a key role in the negative regulation of inflammation and immunity. It is critical for limiting inflammation, by terminating TNF-induced NFkB responses. A20-deficient cells that fail to terminate $\mathrm{TNF}$-induced $\mathrm{NFkB}$ responses are more susceptible to programmed cell death. ${ }^{10}$ A20-deficient mice develop severe inflammation and are hypersensitive to both lipopolysaccharide and TNF, eventually dying prematurely. ${ }^{11}$ $A 20$ has been identified as a primary response gene, expressed in cells stimulated with either proinflammatory cytokines or lipopolysaccharide (LPS). ${ }^{12}$

Because $A 20$ upregulates within 1 hour of an initiated inflammatory response, ${ }^{13}$ it was thought to be a good target for this study; therefore, we examined its expression, using a magnetic field strength of $\sim 40$ Gauss in a range of frequencies (5-30 Hz), on cells from the inflamed macrophage-like cell line RAW 264.7. The RAW cells were induced with gram-negative bacteria LPS, an endotoxin that causes an inflammatory response in the immune systems of animals. Once inflamed, individually plated cells were exposed to PEMF for 1 hour in three independent trials at $5 \mathrm{~Hz}$, 7.8 Hz, $10.8 \mathrm{~Hz}, 15.6 \mathrm{~Hz}, 20.8 \mathrm{~Hz}, 23.4 \mathrm{~Hz}$, and $30 \mathrm{~Hz}$. These frequencies were chosen because ELF-EMFs have been shown to be therapeutic. ${ }^{14,15}$ Afterwards, the cells were assayed for both TNF- $\alpha$ and NFkB production. When the $5 \mathrm{~Hz}$ frequency showed the greatest significant outcome in the downregulation of TNF and NFkB, it was used to test for an effect on $A 20$. In three separate additional trials a quantitative real time polymerase chain reaction (qRT-PCR) was performed to analyze $A 20$ expression.

\section{Materials and methods Cell culture}

RAW 264.7 macrophage-like cells were purchased from the American Type Culture Collection (No TIB-71; American
Type Culture Collection [ATCC], Manassas, VA, USA) and cultured in Dulbecco's modified Eagle medium-high glucose media (DMEM-HG) (HyClone Laboratories Inc, Logan, UT, USA), $10 \%$ fetal bovine serum (FBS), and 1\% penicillinstreptomycin, then incubated in $5 \% \mathrm{CO}_{2}$ at $37^{\circ} \mathrm{C}$ and $100 \%$ humidity until $\sim 80 \%$ confluent. Cells were detached from the culture plates using a cell scraper, then centrifuged at $1500 \mathrm{rpm}$ for 5 minutes and reseeded in four separate culture plates at a density of $5.0 \times 10^{5}$ cells $/ \mathrm{mL}$, in FBS-starved media (DMEM-HG with $1 \%$ penicillin-streptomycin only). After a 16-hour starvation period, the cells were either induced with LPS or left as controls. The cultured RAW cells were challenged for 3 hours (acute-phase inflammatory response was optimized at 3 hours [data not shown]) with LPS to initiate an inflammatory response. After the 3-hour LPS induction period, separate cell plates were exposed to PEMF at different frequencies for 1 hour.

\section{LPS induction}

In order to obtain the optimal dosage concentration for the inflammatory response, a bacterial LPS pellet from Escherichia coli 055:B5 (Sigma-Aldrich, St Louis, MO, USA) was resuspended in Dulbecco's sterile phosphate-buffered saline at a concentration of $1 \mathrm{mg} / \mathrm{mL}$ and applied to the cell solution at serial concentrations of $1.5 \mu \mathrm{g} / \mathrm{mL}, 3 \mu \mathrm{g} /$ $\mathrm{mL}, 5 \mu \mathrm{g} / \mathrm{mL}, 8 \mu \mathrm{g} / \mathrm{mL}$, and $10 \mu \mathrm{g} / \mathrm{mL}$, and then incubated for 3 hours in $5 \% \mathrm{CO} 2$ at $37^{\circ} \mathrm{C}$ and $100 \%$ humidity. NFkB assay (NFkB (p65) Transcription Factor Assay Kit, catalog \#89859; Thermo Fisher Scientific, Waltham, MA, USA) was used to test NFkB activation in the inflammatory response. No significant cell death was seen after testing the LPSinduced cell population using the Cell Titer 96 Aqueous NonRadioactive Cell Proliferation Assay (MTS) (catalog \#G3580; Promega Corp, Fitchburg, WI, USA) (data not shown).

\section{PEMF exposure}

A PEMF device (Figure 1A), consisting of a pair of $14 \mathrm{~cm}$ diameter coils placed $7 \mathrm{~cm}$ apart (Figure 1B), was constructed with 2400 turns of copper wire, in the form of a Helmholtz coil. The coils were driven by an alternating current power supply with adjustable frequency and amplitude. From the coil center inside the $4 \mathrm{~cm}$ coil region, the uniform field strength was measured to be approximately 40 Gauss (Figure 1C). By increasing or decreasing the voltage, the coils were able to emit various frequencies in the sub-ELF-EMF range of $5 \mathrm{~Hz}$ to $30 \mathrm{~Hz}$. Each coil carried a $50 \%$ duty cycle square wave in the same direction (Figure 1D). The PEMF was characterized using a Gauss meter (Sypris Model 5180; 
A

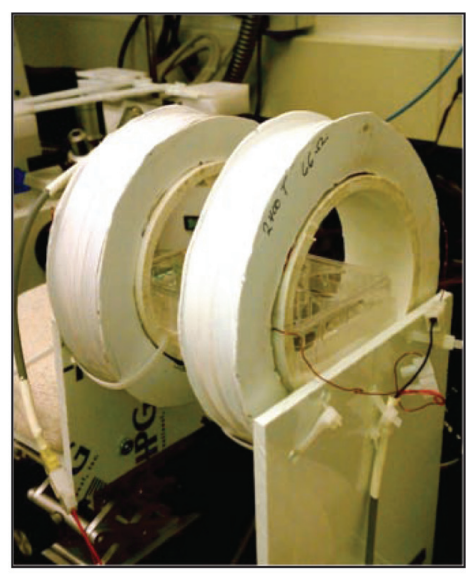

C

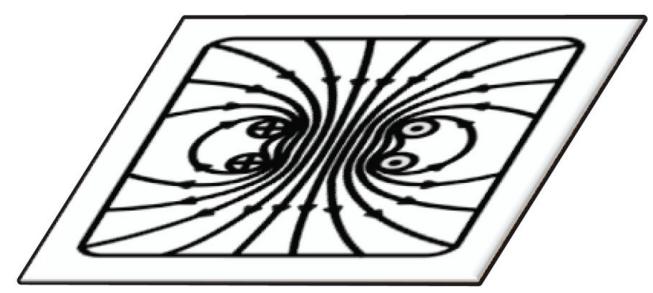

B

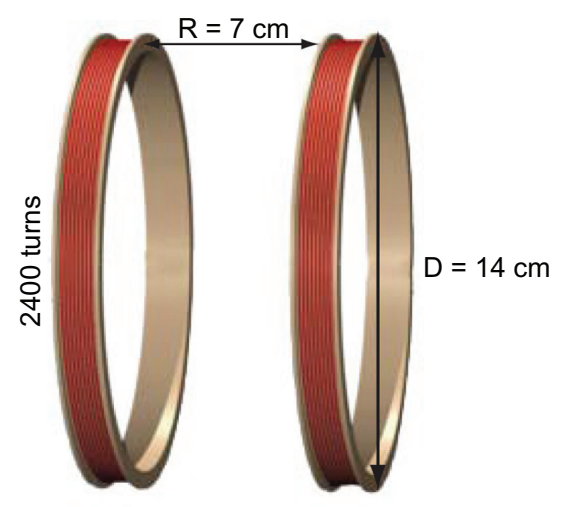

D

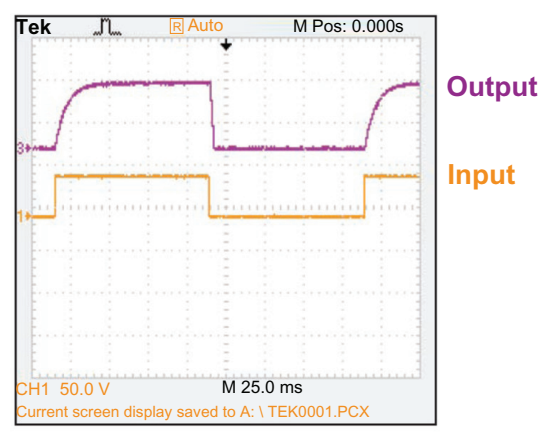

Figure I (A) The PEMF device was designed as a Helmholtz coil to hold a 6-well cell plate. (B) Two coils spaced half the distance of the diameter of the coils emitted a (C) uniform magnetic field. (D) The $5 \mathrm{~Hz}$ pulsed waveform.

Abbreviation: D, diamater; PEMF, pulsed electromagnetic field; R, radius.

Pacific Scientific-OECO, Milwaukie, OR, USA) to determine the average surface field density of $\sim 40$ Gauss. The frequency was determined using an oscilloscope (Model TDS 20248; Tektronix Inc, Beaverton, OR, USA). Experiments were performed under ambient conditions. After exposure to PEMF, a live/dead cell assay was performed using calcein acetomethoxy (catalog \# C697959; Life Technologies, Carlsbad, CA, USA) showing no significant change in cell viability (data not shown). Measurements were taken using a Spectramax M5 plate reader (Molecular Devices LLC, Sunnyvale, CA, USA), at $428 \mathrm{~nm}$ excitation level and $520 \mathrm{~nm}$ emission level. Control samples were kept in the same conditions without exposure to PEMF. A custom built thermocouple was used to ensure a consistent $37^{\circ} \mathrm{C}$ temperature during this process. Background EMF was measured to average the same as Earth's $\sim 0.05$ Gauss.

\section{Experimental groups}

Four experimental groups were set up as follows: (1) RAW macrophages were used as the negative control; (2) RAW macrophages induced with LPS were used as the positive control; (3) RAW macrophages exposed to a magnetic field were one treatment group; and (4) RAW macrophages induced with LPS and exposed to a magnetic field were the other treatment group. For all experiments, four polystyrene tissue-cultured treated 6-well plates were placed directly in the center of the magnetic field with cells only in the four outer wells (Figure 2). The two center wells were empty to assure the uniform cell exposure to PEMF of the four outer wells. The control groups were placed in identical but separate conditions away from PEMF exposure. Three independent trials were run at each of the various frequencies

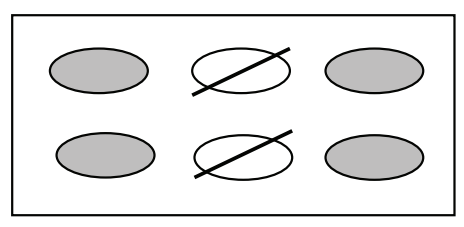

Figure 2 Cells were plated in 6-well plates in the four outer wells only, to assure uniform exposure to the magnetic field. 
(5.1 Hz, 7.8 Hz, 10.8 Hz, 15.6 Hz, 20.8 Hz, 23.4 Hz, and $30 \mathrm{~Hz}$ ). After 1 hour of continuous PEMF exposure at each of these frequencies, the supernatant was extracted from the cell plates, and a multianalyte enzyme-linked immunosorbent assay (ELISA, catalog \# SEM-03113A, SA Biosciences, Valencia, CA, USA) was used to test for TNF- $\alpha$ production. Cell lysate from the same trials was used for detection of $\mathrm{NFkB}$. Separate trials were run to test for expression of $A 20$, after discovering the significance of the $5.1 \mathrm{~Hz}$ frequency.

\section{Detection of cell signaling}

NFkB measurements were obtained using a NFkB assay. The NFkB transcription factor assay used detects active NFkB in both the primary antibody p65 and a secondary horseradish peroxidase (HRP) conjugated antibody. The measurement of TNF- $\alpha$ production was obtained using a Mouse Inflammatory ELISA (catalog \#SEM-03113 A; Qiagen, Venlo, The Netherlands), which measures an individual protein analyte using a standard sandwich ELISA technique. The ELISA analyzed TNF- $\alpha$ using a conventional protocol, where the capture antibodies bind to specific proteins. The color development was read at an absorbance level of $450 \mathrm{~nm}$. Since possible turbidity (which goes uncorrected in an $450 \mathrm{~nm}$ reading ELISA) may yield an artificially high signal, we subtracted the $450 \mathrm{~nm}$ reading from the $570 \mathrm{~nm}$ reading, to correct for any minor optical imperfections in the ELISA plate.

\section{RNA extraction}

To extract and purify ribonucleic acid (RNA), $350 \mu \mathrm{L}$ of the cell lysate samples were processed with the RNeasy Plus Mini Kit (catalog \#74134; Qiagen) according to the manufacturer's instructions, with slight modification for elution volume. RNA quality and concentration was measured using a Nanodrop 2000 Spectrophotometer (Thermo Fisher Scientific). Purified RNA was eluted in $50 \mu \mathrm{L}$ elution buffer and stored at $-80^{\circ} \mathrm{C}$.

\section{Complementary deoxyribonucleic acid (cDNA) synthesis}

cDNA was generated from RNA extraction, using a master mix of $2 \mu \mathrm{L} 10 \mathrm{X}$ random primers, $2 \mu \mathrm{L} 10 \mathrm{X}$ reverse transcriptase (RT) buffer, $0.8 \mu \mathrm{L} 10 \mathrm{mM}$ deoxyribonucleotide triphosphate (dNTP), $10 \mu \mathrm{L}$ of RNA and distilled water, and then incubated in a Peltier Thermal Cycler (PTC-200 DNA Engine ${ }^{\circledR}$, Bio-Rad Laboratories Inc, Hercules CA, USA). The solution was then added to $1 \mu \mathrm{L}$ Superscript $^{\circledR}$ II (catalog \#18064-014; Life Technologies) and incubated at $25^{\circ} \mathrm{C}$ for 10 minutes, then at $42^{\circ} \mathrm{C}$ for 50 minutes, then at $70^{\circ} \mathrm{C}$ for 15 minutes, and then stored at $-20^{\circ} \mathrm{C}$ until qRT-PCR was conducted. The primers for the measurement of the steady state levels of mRNA of the A20/TNFAIP3 gene product were forward: 5'-GCA AGG CTG GGA CCA CG - 3' and reverse: 5' TTG GGT AAG TTA GCT TCA TCC AATT -3' (database accession number 7427750; Eurofins MWG Operon, Huntsville, AL, USA ).

\section{qRT-PCR}

A20 gene expression was quantified using cDNA from cell samples by qRT-PCR. A Sequence Detection System 7300 (Life Technologies) was used for amplification and specific sequence detection. Forward and reverse PCR primers were used in a master mix of $8 \mu \mathrm{L}$ of distilled water, $10 \mu \mathrm{L}$ SYBR green (Life Technologies), $0.5 \mu \mathrm{L}$ each of forward primer (GCA AGG CTG GGA CCA CG) and reverse primer (TTG GGT AAG TTA GCT TCA TCC AATT), and $1 \mu \mathrm{L}$ cDNA for a total volume of $20 \mu \mathrm{L}$. This master mix was used with both glyceraldehyde phosphate dehydrogenase (GAP DH), which was used as the endogenous gene; and $A 20$, the target gene. Cycling parameters were: 2 minutes, $94^{\circ} \mathrm{C} ; 30 \mathrm{sec}, 94^{\circ} \mathrm{C} ; 30 \mathrm{sec}, 55^{\circ} \mathrm{C}$ and $30 \mathrm{sec}, 72^{\circ} \mathrm{C}$, for 34 times; and finally, 10 minutes, $72^{\circ} \mathrm{C}$. GAP DH primers were purchased from Applied Biosystems/Life Technologies.

\section{Statistical analysis}

All data measured are presented as mean $+/-$ standard error of the mean, for $\mathrm{n}=4$ samples. For all assays, a one-way analysis of variance (ANOVA) with Tukey's post hoc test was used to assess the differences between the controls and the cells exposed to the magnetic field, with $P<0.05$ considered statistically significant for all tests.

\section{Results}

Three independent trials were run at frequencies of $5.1 \mathrm{~Hz}$, $7.8 \mathrm{~Hz}, 10.8 \mathrm{~Hz}, 15.6 \mathrm{~Hz}, 20.8 \mathrm{~Hz}, 23.4 \mathrm{~Hz}$, and $30 \mathrm{~Hz}$ respectively. Cytokine assay shows a statistical significance $(P<0.05)$ in the down regulation of TNF- $\alpha$ between the baseline positive controls (RAW cells and LPS) and the 5.1 Hz-treated positive controls (RAW cells and LPS and magnetic field exposure) (Figure 3). Results show that after PEMF exposure to $5.1 \mathrm{~Hz}$ and $7.8 \mathrm{~Hz}$, there was a maximum decrease (of $37 \%$ ) in the production of TNF- $\alpha$; however, no significant decrease was observed at $10.8 \mathrm{~Hz}, 15.6 \mathrm{~Hz}$, $20.8 \mathrm{~Hz}, 23.4 \mathrm{~Hz}$, or $30 \mathrm{~Hz}$. 


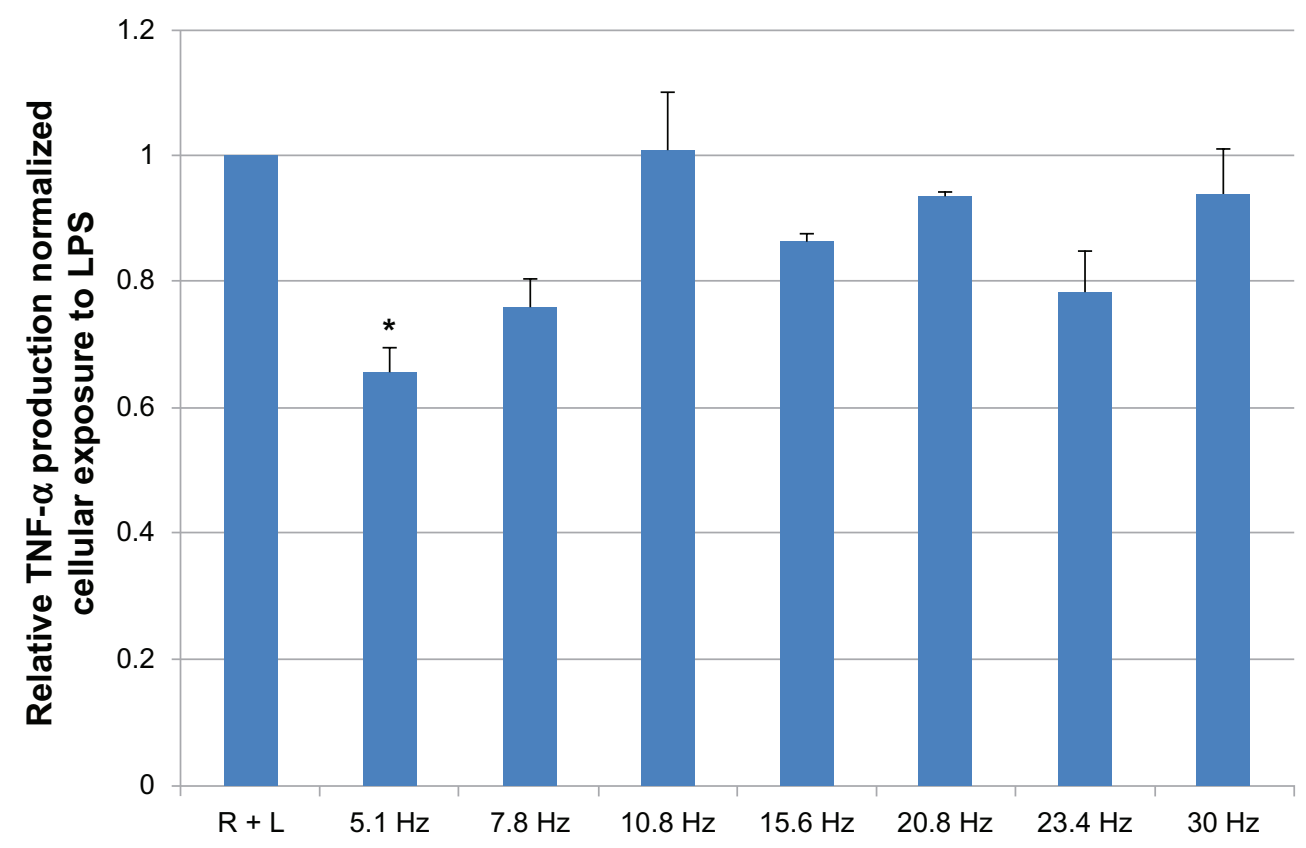

Figure 3 All treatments were normalized to baseline positive control $(\mathrm{R}+\mathrm{L})$.

Notes: $\mathrm{N}=4$, for all samples. Results show that after PEMF exposure to $5.1 \mathrm{~Hz}$, there was a maximum decrease (of $37 \%$ ) in TNF- $\alpha$ level. Error bars $=$ standard error. $* P<0.05$.

Abbreviations: PEMF, pulsed electromagnetic field; R + L, RAW cells induced with lipopolysaccharide; RAW, RAW 264.7 cell line; TNF- $\alpha$, tumor necrosis factor-alpha.

Activation of NFkB in response to PEMF showed similar outcomes (Figure 4). Again, significant levels of NFkB were downregulated at $5.1 \mathrm{~Hz}$ as compared with the positive control (RAW cells and LPS), resulting in a $60 \%$ decrease in NFkB levels. Three additional trials were run using $5 \mathrm{~Hz}$ treatment to test the effect of PEMF on the genetic expression of $A 20$, due to its role as a critical negative regulator of NFkB. The results from qRT-PCR showed no statistically significant difference in the downregulations of A20, although a downward trend appeared (Figure 5).

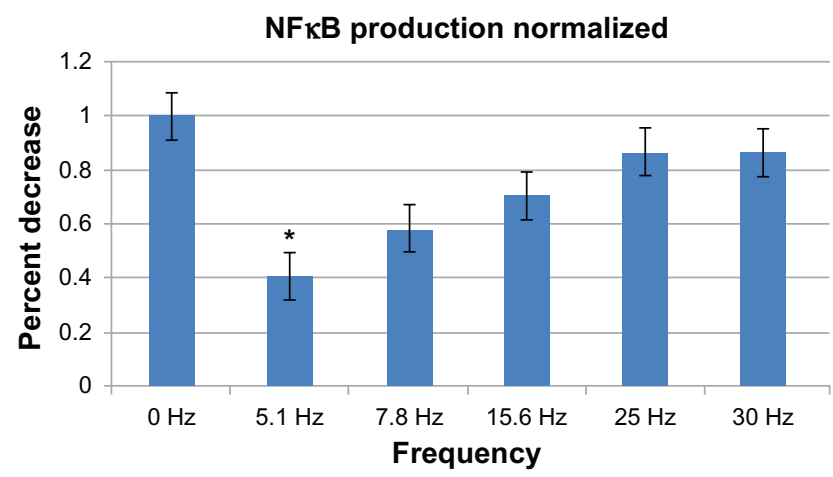

Figure 4 NFkB production in RAW cells exposed to various frequencies of PEMF normalized to the production of NFkB with no magnetic field exposure $(R+L)$. Notes: Results show that at $5 \mathrm{~Hz}$, there was a maximum decrease (of 60\%) in NFkB level. Three independent trials were run, with $n=4$ for all samples. Significance was measured using one-way ANOVA for $P<0.05$. $* P<0.05$.

Abbreviations: ANOVA, analysis of variance; NFkB, nuclear factor kappa beta; PEMF, pulsed electromagnetic field; R + L, RAW cells induced with lipopolysaccharide; RAW, RAW 264.7 cell line.

\section{Discussion}

How PEMF interacts with cell signaling and DNA is not well understood; however, the interaction of electric and magnetic fields with membrane components is well documented. ${ }^{16-19}$ It has been suggested that PEMF can

\section{A20 in the presence of PEMF}

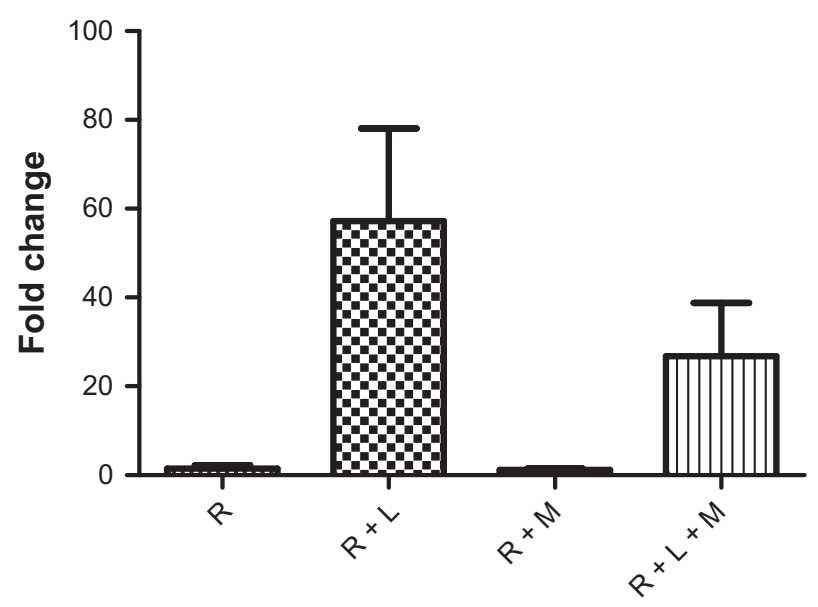

Cell treatment

Figure 5 Three independent trials were run at $5.1 \mathrm{~Hz}$.

Notes: Although not statistically significant, a trend in the decrease of $A 20$ was seen in the presence of I hour of PEMF exposure. $\mathrm{N}=4$ for all samples.

Abbreviations: A20, tumor necrosis factor-alpha-induced protein 3; PEMF, pulsed electromagnetic field; R, RAW 264.7 cells; R + L, RAW cells induced with lipopolysaccharide; $R+L+M$, RAW cells induced with lipopolysaccharide and exposed to magnetic field; $R+M, R A W$ cells exposed to magnetic field. 
be transduced by the cell membrane through an enzyme cascade into a biochemical messenger that can reach the nucleus and alter DNA. ${ }^{4}$ Studies have shown the anti-inflammatory effects of PEMF in vivo, for instance, Selvam et $\mathrm{al}^{15}$ used a coil system emitting a $5 \mathrm{~Hz}$ frequency to treat rats with rheumatoid arthritis for 90 minutes, producing significant antiexudative effect and resulting in the restoration of normal functional parameters. This antiinflammatory effect was reported to be partially mediated through the stabilizing action of PEMF on cell membranes, reflected in the restoration of intracellular $\mathrm{Ca}^{2+}$ levels in blood lymphocytes. Other investigators have suggested that direct current and ELF-EMF can interact with cells through mechanisms that involve extracellular calcium channels. $^{20-22}$ These are plausible theories, but PEMFs are weakened by cell membranes, so membrane processes may not be necessary for the signal to reach the DNA in the nucleus. DNA conduction appears to depend on specific DNA structures because different DNA sequences have varying electrical conductivities. ${ }^{23}$ Blank and Goodman ${ }^{24}$ hypothesized a mechanism based on charge transfer in DNA. They theorized that electrons move in DNA and that specific DNA sequences are associated with the response to PEMF and that further, interaction with electrons could displace them in the H-bonds that hold DNA together, leading to chain separation and initiating transcription. We wanted to test this theory, by examining the effect of PEMF on a certain gene. Knowing that PEMF affected both TNF and $\mathrm{NFkB}$, we looked at particular genes that are expressed through NFkB and chose $A 20$ based on its quick response after insult. Because NFkB is not a single protein but a collection of protein homo- and heterodimers whose activity is regulated by two main pathways, there are two separate directions for signal response to follow. The first pathway applies to dimers that are held dormant in the cytoplasm by specific inhibitors known as IkB. Because IkB is sequestered in an inactive state in the cytoplasm, we chose instead to examine a pathway that led to a gene inside the cell nucleus, which is triggered by TNF. In response to injury or infection, TNF is secreted in bursts by tissue-resident macrophages, and due to a short half-life, ${ }^{25}$ it has been reported that TNF pulses provide for almost 1 hour of NFkB activity. ${ }^{26}$ A20 determines the temporal dose response of the TNF-NFkB signaling pathway by controlling the second phase of NFkB activity. At high levels of expression in stimulated cells, A20 can dampen the amplitude of NFkB activity, but not its duration, suggesting its role in establishing inflammatory tolerance. ${ }^{26}$ Our study shows that after 1 hour exposure to
PEMF, the TNF pulse appeared to be dampened, perhaps affecting the stimulation of NFkB activity. Since $A 20$ determines the temporal dose response of the TNF-NFkB signaling pathway, by controlling the second phase of amplitude of NFkB activity, its upregulation would no longer be required. The effect of PEMF on A20 gene may be playing a less important role than its effect on IkB. NFkB exists in a latent form in the cytoplasm of unstimulated cells, comprising a transcriptionally active dimer bound to inhibitor protein $\mathrm{IkB}$ until it is stimulated to activate. ${ }^{27}$ It could be possible that the PEMF is affecting the IkB protein, preventing the stimulation of $\mathrm{NFkB}$, and causing the downregulation of $A 20$.

\section{Conclusion}

Signaling pathways initiated by bacterial products or cytokine receptors, including those for TNF- $\alpha$ and IL-1, lead to a nuclear accumulation of NFkB and other mediators of inflammatory response associated with sepsis. Since the cell membrane has been proposed as the primary site of transduction of electromagnetic field effects, relevant mechanisms may include changes in cell-membrane binding and transport processes, displacement or deformation of polarized molecules, and modifications in the conformation of biological water. ${ }^{28}$ Intracellular mechanisms have also been hypothesized, based on charge transfer in DNA. If PEMF is able to affect cell signaling due to an disruption caused by cell inflammation, an intact inflammatory response is essential in maintaining normal immunological defense mechanisms. Although inhibition of NFkB activation has been proposed as a therapeutic approach for sepsis, ${ }^{29}$ it is important to note that NFkB is an essential component of normal immune defense, and blocking the regulatory actions of NFkB could cause severe immunosuppression. Modulation in 1-hour doses, rather than blocking of NFkB activation, is apt to be most effective in improving outcomes from sepsis. Treatment should only occur once the inflammatory response has become chronic, when patients with sepsis often show a decreased response to stimuli, such as LPS and other mitogens that resemble endotoxin tolerance. ${ }^{30}$ Because NFkB plays a central role in signaling pathways important in sepsis, PEMF regulation of TNF-NFkB activity may be an appropriate therapeutic target in patients with sepsis.

\section{Acknowledgments}

The authors thank the Caryl Guth Energy Medicine Fund for funding this research and Dennis Dice for producing the EMF generator. 


\section{Disclosure}

The authors report no conflicts of interest in this work.

\section{References}

1. Selvam R, Ganesan K, Narayana Raju KV, Gangadharan A, Manohar BM, Puvanakrishnan R. Low frequency and low intensity pulsed electromagnetic field exerts its antiinflammatory effect through restoration of plasma membrane calcium ATPase activity. Life Sci. 2007;80(26):2403-2410.

2. Markov M, Nindl G, Hazlewood C, Cuppen J. Interactions between electromagnetic fields and immune system: possible mechanism for pain control. In: Ayrapetyan SN, Markov MS, editors. Bioelectromagnetics Current Concepts. Dordrecht: Springer; 2006:213-225.

3. Akan Z, Aksu B, Tulunay A, Bilsel S, Inhan-Garip A. Extremely low-frequency electromagnetic fields affect the immune response of monocyte-derived macrophages to pathogens. Bioelectromagnetics. 2010;31(8):603-612.

4. Blank M, Goodman R. Do electromagnetic fields interact directly with DNA? Bioelectromagnetics. 1997;18(2):111-115.

5. Ross C, Harrison B. The use of magnetic field for the reduction of inflammation: a review of the history and therapeutic results. Alternative Therapies in Health and Medicine. In press 2013.

6. Rubik B. Bioelectromagnetics and the future of medicine. Adm Radiol J. 1997;16(8):38-46.

7. Wallach D, Varfolomeev E, Malinin NL, GoltsevYV, KovalenkoAV, Boldin MP. Tumor necrosis factor receptor and Fas signaling mechanisms. Annu Rev Immunol. 1999;17:331-367.

8. Hayden MS, West AP, Ghosh S. NF-kappaB and the immune response. Oncogene. 2006;25(51):6758-6780.

9. Karin M, Cao Y, Greten FR, Li ZW. NF-kappaB in cancer: from innocent bystander to major culprit. Nature Rev Cancer. 2002;2(4):301-310.

10. Opipari AW Jr, Hu HM, Yabkowitz R, Dixit VM. The A20 zinc finger protein protects cells from tumor necrosis factor cytotoxicity. $J$ Biol Chem. 1992;267(18):12424-12427.

11. Lee EG, Boone DL, Chai S, et al. Failure to regulate TNF-induced NF-kappaB and cell death responses in A20-deficient mice. Science. 2000;289(5488):2350-2354.

12. Dixit VM, Green S, Sarma V, et al. Tumor necrosis factor-alpha induction of novel gene products in human endothelial cells including a macrophage-specific chemotaxin. J Biol Chem. 1990;265(5): 2973-2978.

13. Boone DL, Turer EE, Lee EG, et al. The ubiquitin-modifying enzyme A20 is required for termination of Toll-like receptor responses. Nat Immunol. 2004;5(10):1052-1060.

14. Wahlström O, Knutsson H. A device for generation of electromagnetic fields of extremely low frequency. J Biomed Eng. 1984;6(4): 293-296.

15. Selvam R, Ganesan K, Narayana Raju KV, Gangadharan AC, Manohar BM, Puvanakrishnan R. Low frequency and low intensity pulsed electromagnetic field exerts its antiinflammatory effect through restoration of plasma membrane calcium ATPase activity. Life Sci. 2007;80(26):2403-2410.
16. Blank M, editor. Electric and magnetic field signal transduction in the membrane $\mathrm{Na}^{+}, \mathrm{K}^{+}$-adenosinetriphosphatase. Electromagnetic Fields. Biological Interactions and Mechanisms, Advances in Chemistry. Washington: American Chemical Society; 1995;250:339-348.

17. Blank M. Electric stimulation of protein synthesis in muscle. In: Blank M, editor. Electromagnetic Fields. Biological Interactions and Mechanisms, Advances in Chemistry. Washington: American Chemical Society; 1995;250:143-153.

18. Luben R. Membrane signal-transduction mechanisms and biological effects of low-energy electromagnetic fields. In: Blank M, editor. Electromagnetic Fields. Biological Interactions and Mechanisms, Advances in Chemistry. Washington, DC: American Chemical Society; 1995;250:437-450.

19. Bassett A. Therapeutic uses of electric and magnetic fields in orthopedics. In: Carpenter DO, Ayrapetyan S, editors. Biological Effects of Electric and Magnetic Fields: Beneficial and Harmful Effects. San Diego, CA: Academic Press; 1994;2:13-48.

20. Cho MR, Thatte HS, Silvia MT, Golan DE. Transmembrane calcium influx induced by ac electric fields. FASEB J. 1999;13(6):677-683.

21. Cho M, Marler JP, Thatte HS, Golan DE. Control of calcium entry in human fibroblasts by frequency-dependent electrical stimulation. Front Biosci. 2002;7:a1-a8.

22. Trollinger DR, Isseroff RR, Nuccitelli R. Calcium channel blockers inhibit galvanotaxis in human keratinocytes. J Cell Physiol. 2002;193(1):1-9.

23. Meggers E, Michel-Beyerle ME, Giese B. Sequence dependent long range hole transport in DNA. J Am Chem Soc. 1998;120(49):12950-12955.

24. Blank M, Goodman R. A mechanism for stimulation of biosynthesis by electromagnetic fields: charge transfer in DNA and base pair separation. J Cell Physiol. 2008;214(1):20-26.

25. Beutler BA, Milsark IW, Cerami A. Cachectin/tumor necrosis factor: production, distribution, and metabolic fate in vivo. J Immunol. 1985;135(6):3972-3977.

26. Werner SL, Kearns JD, Zadorozhnaya V, et al. Encoding NF-kappaB temporal control in response to TNF: distinct roles for the negative regulators IkappaBalpha and A20. Genes Dev. 2008;22(15):2093-2101.

27. Baeuerle P, Henkel T. Function and activation of NF-kappa B in the immune system. Annu Rev Immunol. 1994;12:141-179.

28. Eichwald C, Kaiser F. Model for external influences on cellular signal transduction pathways including cytosolic calcium oscillations. Bioelectromagnetics. 1995;16(2):75-85.

29. Abraham E. Nuclear factor-kappaB and its role in sepsis-associated organ failure. J Infect Dis. 2003;187 Suppl 2:S364-S369.

30. Adib-Conquy M, Adrie C, Moine P, et al. NF-kappaB expression in mononuclear cells of patients with sepsis resembles that observed in lipopolysaccharide tolerance. Am J Respir Crit Care Med. 2000;162(5): 1877-1883.

\section{Publish your work in this journal}

The Journal of Inflammation Research is an international, peer-reviewed open-access journal that welcomes laboratory and clinical findings on the molecular basis, cell biology and pharmacology of inflammation including original research, reviews, symposium reports, hypothesis formation and commentaries on: acute/chronic inflammation; mediators of inflamma-

\section{Dovepress}

tion; cellular processes; molecular mechanisms; pharmacology and novel anti-inflammatory drugs; clinical conditions involving inflammation. The manuscript management system is completely online and includes a very quick and fair peer-review system. Visit http://www.dovepress.com/ testimonials.php to read real quotes from published authors. 